\title{
Treating neovascular age-related macular degeneration in the era of COVID-19
}

\author{
Fares Antaki ${ }^{1}$ (1) Ali Dirani $^{2}$ (i) \\ Received: 29 March 2020 / Revised: 4 April 2020 / Accepted: 8 April 2020 / Published online: 21 April 2020 \\ (C) Springer-Verlag GmbH Germany, part of Springer Nature 2020
}

\section{Dear Editor,}

With the current coronavirus disease (COVID-19) pandemic, ophthalmologists are confronted by great challenges. We have the responsibility of providing care while protecting ourselves and respecting our societal duties by not acting as vectors of the disease. The American Academy of Ophthalmology recommended that ophthalmologists cease providing any treatment other than urgent or emergent care [1]. Retina specialists face additional challenges: the elderly patients most commonly in need of anti-VEGF injections are also at the greatest risk of morbidity and mortality from COVID-19 [2].

Ophthalmology clinics are often very crowded. Consultations are lengthy and require patient interaction with multiple ophthalmic care providers. All those interactions are potential scenarios for cross-infection. Recently, Lai et al. described three-level control measures to minimize COVID-19 spread among eye care providers and patients: administrative control to lower patient attendance, a triage system to identify at-risk patients, and promotion of the appropriate use of personal protective equipment [3]. The use of protective shields on slit-lamps has also been described to act as barriers to droplets [3]. In this letter, we propose an adapted treatment strategy for neovascular age-related macular degeneration (nAMD) to reduce the spread of COVID-19. Our strategy is a modified combination of "treat-and-extend" (TER) [4] and "observe-and-plan" (OAP) [5] regimens, that we coin "treatand-plan" (TAP). TAP has three main objectives: shortening visit time to decrease contact times between patients and care

Ali Dirani

drdirani@gmail.com

1 Department of Ophthalmology, Centre Hospitalier de l'Université de Montréal (CHUM), Montreal, QC, Canada

2 Department of Ophthalmology, Centre Universitaire d'Ophtalmologie, Hôpital du Saint-Sacrement, CHU de Québec Université Laval, Québec, Canada providers, decreasing waiting area congestion to allow for appropriate distancing between patients, and maintaining visual acuity (VA) improvements and stabilization throughout the follow-up period.

TAP is described in Fig. 1. We propose two types of visits: assessment visits and in-and-out injection visits. Assessment visits should be allocated time as per standard practice as those include check-in (5 min), VA (5 min), dilation (10 min), optical coherence tomography (OCT) (5 min), ophthalmic examination, and injection (10 min). In the absence of wait times, the overall visit duration could be up to $40 \mathrm{~min}$. For OCT evaluations, we recommend obtaining only the necessary scans (e.g., macular cube) to avoid prolonged interaction with the ophthalmic photographers. In-and-out injection visits refer to express clinic visits during which the patient only receives the scheduled intravitreal injection, without any examination or testing. Prior to the injection, the patient must be asked about symptoms of uveitis in an attempt to rule out intraocular inflammation. In the absence of wait times, such visits should not last longer than 10 min (check-in + injection). Assessment visits include the baseline visit and subsequent assessment visits, during which patients are allocated to a fixed-interval regimen based on disease activity and receive the first injection of their allocated regimen. The interval between the last injection of the current fixed-interval regimen and the next assessment visit is equal to the interval between consecutive injections. The available fixed-interval regimens (number of injections $\times$ interval in weeks) are as follows: $3 \times \mathrm{q} 4,3 \times \mathrm{q} 6,3 \times \mathrm{q} 8,2 \times \mathrm{q} 10$, and $2 \times \mathrm{q} 12$. Intervals range from 4 to 12 weeks because there is no available data on the reliability of longer intervals. Given the risk of undiagnosed recurrence between two assessment visits, patients should be assessed at least every 6 months. Thus, only 2 injections are planned for the q10- and q12-week regimens. In case of bilateral disease, the eye with more severe disease will dictate the treatment interval.

The advantage of TAP over TER and OAP is the less frequent number of assessment visits required to monitor disease activity [6]. Such visits are often longer and may increase the 


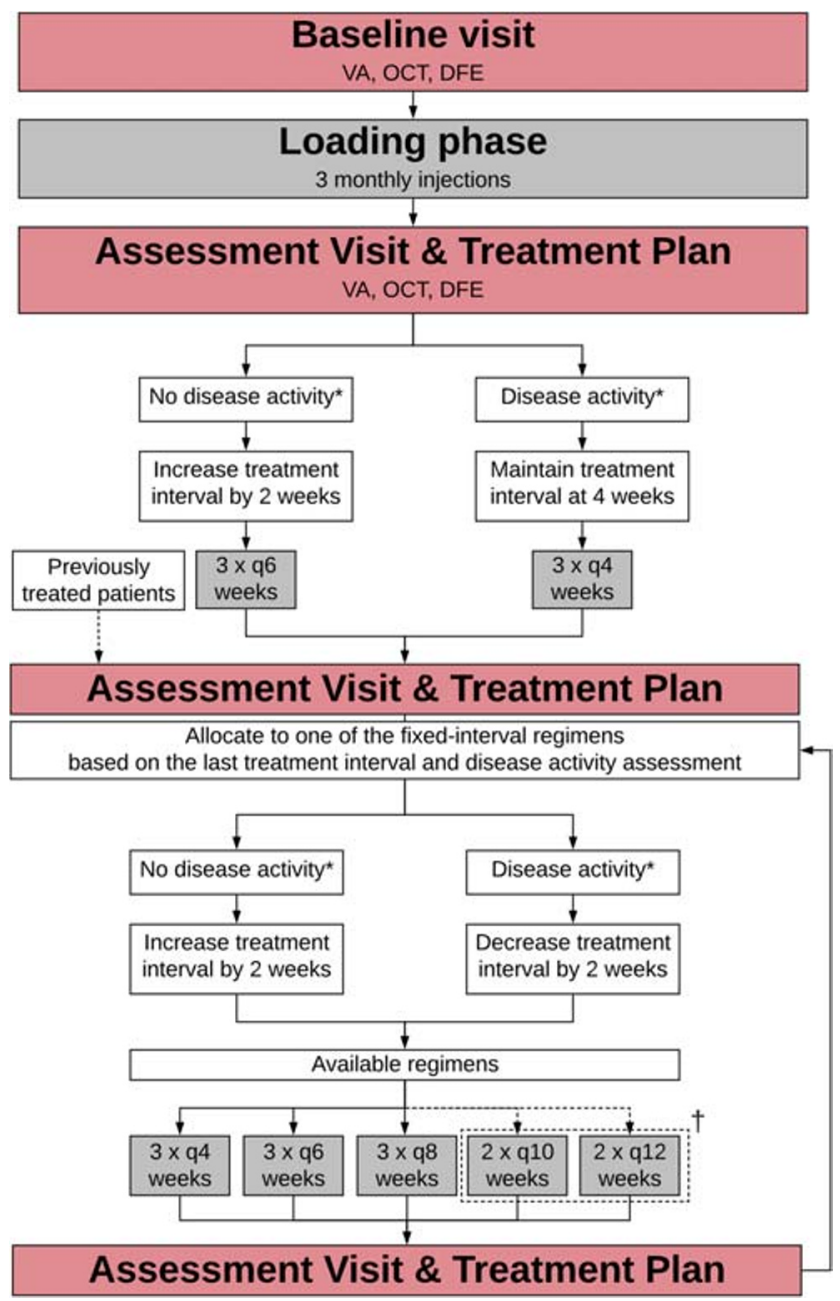

Fig. 1 The proposed treat-and-plan (TAP) regimen for the treatment of nAMD during the COVID-19 pandemic. New patients are assessed during a baseline visit and receive a loading dose of three monthly intravitreal injections. The monthly injections are performed according to the in-andout injection visit model. A regular assessment and treatment plan visit is held 4 weeks after the last injection. During this visit, disease activity is assessed and the patient is allocated to a fixed-interval regimen accordingly. The first injection of this fixed-interval regimen $(3 \times \mathrm{q} 6$ weeks or $3 \times \mathrm{q} 4$ weeks) is carried out during the same visit. The subsequent injections are performed according to the in-and-out injection visit model. The interval between last injection of the previous fixed-interval regimen and the next assessment visit is equal to the previously set interval. During subsequent assessment visits, the patient is allocated to one of the fixedinterval regimens based on disease activity and receives the first injection of the next fixed-interval regimen. *Disease activity is defined as follows: exudative signs on OCT (intraretinal or subretinal fluid) or on fundus examination (new macular hemorrhage). ${ }^{\dagger} 2 \times \mathrm{q} 10$ weeks and $2 \times \mathrm{q} 12$ weeks are possible fixed-interval regimens for subsequent assessment visits. VA visual acuity, OCT optical coherence tomography, DFE dilated fundus examination

risk for cross-infection. Another advantage of TAP over OAP is the proactive approach that allows the continuity of injections without waiting for disease activity to recur [7]. This may be advantageous for the final visual outcome. A limitation of the less frequent assessments in the TAP regimen is the potential risk of missing disease recurrence/persistence that would have otherwise necessitated interval shortening in TER. We base the safety and efficacy of TAP on previously published results for the OAP regimen since TAP will be similar to OAP during the second year of treatment. OAP has been shown to be effective in maintaining good visual acuity results despite lower number of assessment visits for up to 2 years $[8,9]$. In the TAP regimen, slit-lamp assessment is not required during in-and-out injection visits. However, clinicians must consider the risk/benefit of eliminating clinical examination in the context of the current pandemic while keeping in mind recent concerns of possible inflammatory side effects related to novel anti-VEGF agents [10].

We recognize that this treatment strategy might not be applicable at every time and place. The COVID-19 pandemic is a rapidly evolving situation and ophthalmologists must quickly adapt to recommendations by their local healthcare authorities. We believe that this proposed treatment strategy might be a useful tool to adequately manage patients with nAMD during this crisis, especially if the pandemic proves to be lengthy. Nonetheless, as physicians, we should always take into consideration individual patient risks and current societal circumstances, and always abstain from causing harm to patients (Primum non nocere).

\section{Compliance with ethical standards}

Conflict of interest The authors declare that they have no conflict of interest.

\section{References}

1. New recommendations for urgent and nonurgent patient care. (2020) American Academy of Ophthalmology. https://www.aao. org/headline/new-recommendations-urgent-nonurgent-patientcare. Accessed 27 March 2020

2. Member alert regarding the COVID-19 pandemic. (2020) American Society of Retina Specialists. https://www.asrs.org/ practice/asrs-member-alert-regarding-covid-19-pandemic. Accessed 27 March 2020

3. Lai THT, Tang EWH, Chau SKY, Fung KSC, Li KKW (2020) Stepping up infection control measures in ophthalmology during the novel coronavirus outbreak: an experience from Hong Kong. Graefes Arch Clin Exp Ophthalmol. https://doi.org/10.1007/ s00417-020-04641-8

4. Spaide R (2007) Ranibizumab according to need: a treatment for age-related macular degeneration. Am J Ophthalmol 143(4):679680. https://doi.org/10.1016/j.ajo.2007.02.024

5. Mantel I, Niderprim SA, Gianniou C, Deli A, Ambresin A (2014) Reducing the clinical burden of ranibizumab treatment for neovascular age-related macular degeneration using an individually planned regimen. Br J Ophthalmol 98(9):1192-1196. https://doi. org/10.1136/bjophthalmol-2013-304556

6. Mantel I (2015) Optimizing the anti-VEGF treatment strategy for neovascular age-related macular degeneration: from clinical trials to real-life requirements. Transl Vis Sci Technol 4(3):6. https://doi. org $/ 10.1167 /$ tvst.4.3.6 
7. Freund KB, Korobelnik JF, Devenyi R, Framme C, Galic J, Herbert E, Hoerauf H, Lanzetta P, Michels S, Mitchell P, Mones J, Regillo C, Tadayoni R, Talks J, Wolf S (2015) Treat-and-extend regimens with anti-VEGF agents in retinal diseases: a literature review and consensus recommendations. Retina 35(8):1489-1506. https://doi. org/10.1097/IAE.0000000000000627

8. Parvin P, Zola M, Dirani A, Ambresin A, Mantel I (2017) Two-year outcome of an observe-and-plan regimen for neovascular agerelated macular degeneration treated with Aflibercept. Graefes Arch Clin Exp Ophthalmol 255(11):2127-2134. https://doi.org/ 10.1007/s00417-017-3762-2

9. Gianniou C, Dirani A, Ferrini W, Marchionno L, Decugis D, Deli A, Ambresin A, Mantel I (2015) Two-year outcome of an observe- and-plan regimen for neovascular age-related macular degeneration: how to alleviate the clinical burden with maintained functional results. Eye (Lond) 29(3):342-349. https://doi.org/10.1038/eye. 2014.258

10. Update: Brolucizumab's safety under review. (2020) American Academy of Ophthalmology. https://www.aao.org/headline/ brolucizumab-s-safety-under-review. Accessed 4 April 2020

Publisher's note Springer Nature remains neutral with regard to jurisdictional claims in published maps and institutional affiliations. 